\title{
James Prescott Joule e o equivalente mecânico do calor: Reproduzindo as dificuldades do laboratório
}

(James Prescott Joule and the mechanical equivalent of heat: Simulating the difficulties in experimental activities)

\author{
Rafaelle da Silva Souza, Ana Paula Bispo da Silva ${ }^{\varpi}$, Thiago Silva Araujo \\ ${ }^{1}$ Universidade Estadual da Paraíba, Grupo de História da Ciência e Ensino, \\ Departamento de Física, Campina Grande, Paraíba, Brasil \\ Recebido em 30/3/2014; Aceito em 17/5/2014; Publicado em 7/8/2014
}

\begin{abstract}
Apesar das várias controvérsias, o experimento das pás de Joule é considerado um experimento crucial para demonstrar a conservação da energia em sala de aula. Entretanto, na apresentação do experimento, muito da sua complexidade à época da sua execução é negligenciada e apresenta-se apenas o resultado final, desperdiçando um momento excelente para discutir com os estudantes todas as hipóteses e sutilezas envolvidas. Neste trabalho apresentamos o processo de reprodução utilizando materiais atuais de um experimento similar ao de Joule de 1850 em busca do equivalente mecânico do calor. As hipóteses levantadas na replicação do experimento bem como a análise dos dados obtidos mostram a complexidade da ciência, o papel da experimentação na validação de teorias e um aspecto conceitual muito importante como a dificuldade para estabelecer um valor exato do equivalente mecânico do calor. Nossa intenção é mostrar como experimentos históricos podem colaborar para transformar a atividade experimental em sala de aula num ambiente rico para a argumentação e problematização. Palavras-chave: experimentos históricos, história da ciência, James Prescott Joule.
\end{abstract}

Despite many controversies, Joule's paddle-wheel experiment is considered crucial to demonstrate the conservation of energy in the classroom. However, the complexity of the experiment in its epoch is neglected and only the final result is presented, wasting an excellent moment to discuss with students all the hypotheses and subtleties involved in it. In this work we present the process of replication of Joule's 1850 experiment on the mechanical equivalent of heat. We used present-day devices. The hypotheses elaborated during the experiment as well as the data analysis demonstrate the complexity of science and the role of the experiment to validate theories. Also, this replication explores the difficulties in reaching an exact value for the mechanical equivalent of heat. Our intention is to show how historical experiments can collaborate to transform the experimental activity in the classroom into a rich environment to argumentation and inquiry-based teaching.

Keywords: historical experiments, history of science, James Prescott Joule.

\section{Introdução}

Experimentos históricos são considerados como uma oportunidade para associar os benefícios da história da ciência às atividades em sala de aula. Essa associação permite alcançar tanto os estudantes que têm preferência por disciplinas relacionadas à área de humanas, estimulados pelos relatos históricos, como aqueles que preferem atividades experimentais. Heering e Wittje [1] também argumentam que experimentos são cruciais para uma educação científica e têm desempenhado um papel importante no ensino de ciências desde o século XVIII. Nas últimas décadas, o ensino de ciências reconsiderou renovar seus propósitos e levantou-se a questão de considerar tanto a importância do conhecimento científico como também os paradigmas de como a ciência

\footnotetext{
${ }^{1}$ E-mail: anabispouepb@gmail.com.

foi construída no decorrer do tempo. Essa nova perspectiva sobre o ensino de ciências atraiu historiadores e filósofos para exploração a fundo de experimentos históricos, dos instrumentos e experimentação [2].

Filósofos, historiadores e professores de ciências acreditam que a partir da leitura do experimento original, seu contexto e personagem principal - um cientista ou filósofo natural - é possível discutir aspectos epistemológicos da ciência bem como as influências sociais sobre o trabalho científico. Ao reconstruir os experimentos originais ou similares, estudantes podem compreender os conceitos físicos envolvidos e as dificuldades encontradas no trabalho experimental. Conhecer o experimento original, os fatos relacionados a ele e quando foi realizado pela primeira vez pode elucidar 
muitos aspectos do trabalho científico e as fragilidades das teorias. Este tipo de atividade experimental também auxiliaria no desenvolvimento de capacidades argumentativas e de resolução de problemas (inquirybased), enfatizando a provisoriedade do conhecimento científico [3].

No entanto, muitos experimentos históricos não estão bem apresentados na literatura do ensino de ciências ou livros didáticos. A narrativa é simplificada e omitem-se as dificuldades enfrentadas pelo cientista, o que impede uma compreensão mais profunda sobre sua história e as teorias implícitas nele e assumidas $a$ priori.

Considerando sua precisão e sutilezas, o propósito deste trabalho é explorar o experimento histórico realizado por James Prescott Joule (1818-1889) em 1850 para obter o equivalente mecânico do calor. Não é nossa intenção explorar todo o pano de fundo histórico que pode ser associado ao presente experimento, e que pode ser encontrado em várias referências [4-6]. Porém é importante apenas situar em que momento da história da ciência ele ocorreu e porquê muitas vezes é considerado crucial para o estabelecimento do princípio da conservação da energia.

Durante a primeira metade do século XIX vários filósofos naturais ${ }^{\square}$ estavam envolvidos com experimentos que mostravam uma "conversão de forças [l]", como o caso do magnetismo que gerava eletricidade, as reações químicas que geravam eletricidade e calor, etc., que pareciam ocorrer em vários ramos da ciência. Algumas conversões eram utilizadas antes mesmo do século XIX, como por exemplo a conversão do vapor em movimento nas máquinas; ou a pilha de Volta. Mas somente na década de 1830, as diferentes conversões obtidas passaram a ser compreendidas como um processo maior, em que parecia haver uma conexão única entre diferentes "forças naturais". Podem-se listar vários nomes associados aos estudos desta "conversibilidade de forças", como Faraday, Grove, Colding, Mayer, Joule, entre outros [7, p. 100]. Kuhn [7] argumenta que os trabalhos que ocorriam ao mesmo tempo estavam mais direcionados à conversibilidade universal, o que, nas palavras de Grove, significava:

que [qualquer um] dos vários agentes [agencies] imponderáveis [...] calor, luz, eletricidade, magnetismo, afinidade química e movimento $[. .$.$] pode, como uma força, pro-$ duzir os demais ou ser neles convertidos $[7$, p. 102].

Da conversibilidade é possível chegar à conservação considerando "expedientes filosóficos sempre úteis sobre a igualdade das causas e efeitos ou a impossibilidade do movimento perpétuo" [7, p. 102]. Se a conversibilidade não implicasse na conservação, isso significaria a criação de algo a partir do nada, o que contrariava a lógica. Mas não é possível afirmar que os estudos realizados tinha como objetivo comprovar ou demonstrar a conservação da energia, ou estaríamos incorrendo no que se chama de interpretação anacrônica, enxergando nos estudos antigos, conceitos que foram desenvolvidos posteriormente.

Assim, apesar de vários estudiosos estarem trabalhando com as conversões, um prenúncio da ideia de conservação da energia só poderia aparecer naqueles casos em que o trabalho mecânico estivesse envolvido, porque era o que permitia uma mensuração. A relação mensurável entre as conversões era um problema na época. Muitos dos estudiosos tinham a percepção de que haveria uma proporcionalidade nas conversões, mas não conseguiam obtê-la com precisão [7, p. 113-117]. Talvez por este motivo, os trabalhos de Joule e Mayer que buscavam um valor para o equivalente mecânico tenham tido um impacto maior do que as medidas a partir das reações químicas.

Apesar das muitas controvérsias entre Joule e Julius Robert Mayer (1814-1878) sobre quem foi o primeiro a determinar o valor correto do equivalente mecânico do calor, a experiência de Joule, talvez por envolver uma forma mais prática, tem sido adotada inúmeras vezes como determinante no estabelecimento do princípio da conservação da energia [4,5]. Porém, seja nos livros didáticos, nas simulações ou nas propostas de sala de aula, não são discutidos os obstáculos encontrados por Joule, suas medidas reais, e todas as demais considerações necessárias para a realização do experimento, atribuindo-se uma simplificação e reducionismo que contrastam com a riqueza de detalhes que ele envolve. ${ }^{\text {I }}$

Com o objetivo de tentar entender como o experimento pode levar a algum resultado e sua complexidade, decidimos por reproduzi-lo. No entanto, o experimento original não é fácil de reconstruir, como será detalhado posteriormente, e por isso desenvolvemos um similar, que tinha os mesmos princípios físicos, mas dispositivos e materiais atuais. Percebemos que, mesmo com materiais mais sofisticados, o aumento da temperatura foi insignificante, o que nos leva a olhar para o experimento original de Joule sob outras perspectivas, como suas ideias a priori, os desafios, as soluções, etc., considerando o contexto em que ele se encontrava e seus objetivos. Estes resultados podem ser um ponto de par-

\footnotetext{
${ }^{2}$ Apesar do nome "cientista" já fazer parte das atividades científicas, muitos ainda o consideravam pejorativo, como Faraday, por exemplo, e se autodenominavam filósofos experimentais [8].

${ }^{3} \mathrm{O}$ termo força utilizado aqui não corresponde ao que adotamos atualmente. Seria equivalente ao que hoje chamamos "energias". Portanto, estará sempre entre aspas.

${ }^{4}$ Vários exemplos de reconstruções do experimento de Joule podem ser encontrados no sítio www.youtube.com . Exemplos de algumas visões extremamente simplificadas (e distorcidas) aparecem em http://wWw.youtube.com/watch?v=V44\{_\}AtPKpGo; nttp: //wWw.youtube.com/watch?v=mRu4Wdi5IP8 e http://wWw.youtube.com/watch?v=wktnigr260k.
} 
tida inicial para uma discussão em sala de aula sobre o papel dos experimentos na ciência e a complexidade dos trabalhos científicos.

\section{O experimento original de James Joule}

James Prescott Joule nasceu em Manchester em 1818 e morreu em Sale em 1889. Descendente de proprietários rurais (cervejeiros), recebeu toda sua educação elementar em casa, juntamente com seu irmão mais velho, onde tiveram como professor John Dalton, químico reconhecido na época. Após o casamento em 1847, residiu em diferentes domicílios na região de Manchester, sem exercer qualquer profissão ou atuar na cervejaria da família. Começou a se dedicar às investigações de fenômenos físicos e químicos muito cedo, realizando seus experimentos em laboratórios que instalava em suas residências ou na cervejaria. Os trabalhos que realizou no período entre 1837 e 1847 são o maior destaque na sua carreira [9]. Estão incluídas, inicialmente, as investigações sobre eletroímãs e motores eletromagnéticos. Posteriormente, passou a estudar os efeitos térmicos envolvidos com o eletromagnetismo.

Alguns trabalhos de Joule que envolveram transformações químicas, baseavam-se no aquecimento da água quando associada a um par eletroquímico ou reação eletrolítica. Joule encontrou uma relação para a produção de calor por uma corrente voltaica através das medidas de temperatura da água em contato com uma porção espiralada de um circuito. Utilizando termômetros sensíveis e fazendo uso de suas habilidades, Joule encontrou as variações de temperatura em relação às variações da intensidade da corrente e da resistência. Seu estudo sistemático sobre efeitos térmicos e passagem de corrente, que culminaram no seu trabalho final de janeiro de 1843, não permitiam determinar a natureza do calor, um dos debates efervescentes na época e dos quais ele tinha conhecimento [10]. Os experimentos não permitiam concluir se o calor poderia ou não ser uma substância [9]. Somente com o experimento que realizou posteriormente, em que isolou um motor eletromagnético num recipiente com água [11], pôde chegar à conclusão de que o calor produzido somente poderia ser de origem dinâmica, e que haveria uma conversão entre "forças" eletromagnéticas e calor.

Ainda na repetição dos experimentos com reações químicas, Joule destaca a necessidade de realizar várias correções para que os valores encontrados, entre calor e o fenômeno químico, possam ser equivalentes de forma precisa, dando indícios de uma certa "compensação de forças" que poderíamos entender agora como "conservação da energia". Por exemplo, ele argumenta que uma correção deve ser feita se a temperatura da água não estiver exatamente igual a temperatura do ar do ambiente, pois pode haver calor emitido por radiação.
Tal compensação, ou equivalência, de "forças", estava presente em outros trabalhos, em diferentes programas de pesquisa e permeava os estudos de Joule como um conhecimento anterior ao experimento, principalmente quando pode-se considerar que ele estava inserido num ambiente rico em discussões sobre reações químicas e produção de calor. Há de se lembrar que Joule teve como professor John Dalton e participava ativamente das reuniões da Royal Society [12, p. 343347 .

Entretanto, as investigações envolvendo eletricidade e reações químicas, realizadas por Joule tinha como fim a construção de uma máquina utilizando os fenômenos eletromagnéticos, que pudesse oferecer um rendimento maior do que aquelas que realizavam uma tarefa a partir da queima do carvão. Apesar de não atingir seu objetivo, já que as máquinas que utilizavam zinco (bateria) acabavam por ser mais caras do que as baseadas na queima do carvão, estas investigações permitiram que Joule se familiarizasse com as diferentes conversões das "forças naturais" entre si.

Nos trabalhos posteriores, outros interesses de Joule surgem e ele começa a buscar alguma equivalência - ou proporcionalidade - entre os fenômenos, como a relação entre o calor de combustão na formação de um eletrólito e a resistência à condução elétrica. Em 1843, após vários experimentos envolvendo eletricidade e magnetismo, ele apresenta um trabalho diante da British Association for the Advancement of Science, em que conclui:

Tendo provado que calor é gerado pela máquina eletromagnética, e que através do poder indutivo do magnetismo podemos diminuir ou aumentar à vontade o calor devido a mudanças químicas, torna-se um objeto de grande interesse questionar se há uma razão constante entre ele [o calor] e a potência mecânica ganha ou perdida $[13$, p. 149].

Portanto, Joule já considerava teoricamente a possibilidade de existência da equivalência entre calor e outros fenômenos. Parte desse "pressuposto teórico" estava baseado em considerações metafísicas, muitas associadas à Naturphilosophie, uma tradição filosófica com origem no Romantismo alemão [7, p. 119]. Assim como outros imersos nessa tradição filosófica, Joule assumia que deveria haver algum fim nas coisas existentes na natureza, criada por um Ser Divino [13, p. 158]. Algumas ideias da Naturphilosophie indicavam uma unicidade da Natureza, um princípio único, uma "equivalência de forças". Alguns interpretavam como a busca por "um princípio geral pelo qual diferentes fenômenos (luz, radiação quente, interação elétrica e magnética) pudessem ser explicados" [14]. Já Joule não buscava um princípio que fosse válido para vários fenômenos, 
mas uma relação entre os diferentes fenômenos de modo a ligá-los.

Sua linha de pensamento o levou a considerar as relações entre calor e trabalho mecânico, mas seu conhecimento superficial de matemática tornava suas observações limitadas, o que também ocorria com suas atividades experimentais, que buscavam uma relação simples entre as variáveis envolvidas. Os resultados de suas investigações foram escritos em uma série de artigos que culminaram na sua grande memória sobre equivalente mecânico do calor, publicada em 1850. Em todos os artigos, Joule descreve minuciosamente os equipamentos utilizados, o modo como as medidas foram obtidas e apresenta várias tabelas com os resultados. Em 1850, foi eleito membro da Royal Society, desfrutando de posição acadêmica de autoridade [11].

O experimento explorado neste trabalho foi apresentado por Joule para a Royal Society em 1849 e publicado na Philosophical Transactions em 1850 [15]. Antes deste experimento, Joule tinha obtido um valor para o equivalente mecânico do calor através de experimentos eletromagnéticos, mas que não poderia ser considerado muito preciso, como discutimos antes [12]. No en- tanto, ele queria encontrar uma relação entre o trabalho mecânico e a produção de calor, em busca de respostas também quanto à natureza do calor, discussão em pauta na época e sobre a qual ele faz uma introdução no artigo do experimento, buscando justificar-se ao tentar encontrar um valor mais preciso do que o de Rumford. Durante anos, ele dedicou-se a encontrar a melhor e mais precisa forma de medir o calor produzido por um fluido quando submetido à fricção, elaborando experimentos que utilizavam água ou mercúrio.

Uma descrição completa do experimento pode ser encontrada em [15], bem como na sua obra completa [13, p. 298-328]. E constituído por um vaso de cobre para colocar água (Fig. 1 d) com uma sequência de pás no seu interior (Fig. 1 b e c). A sequência de pás está ligada por um eixo de manivela e polias, em que a corda é enrolada. Para executar o movimento das pás, as polias são associadas aos pesos pendurados abaixo delas (Fig. 1a). Quando o peso é liberado, a gravidade faz o trabalho mecânico, girando a manivela e girando a roda de pás, que agita a água dentro do vaso. Um termômetro é inserido na tampa do cilindro para medir a temperatura (a abertura b na Fig. 1d).

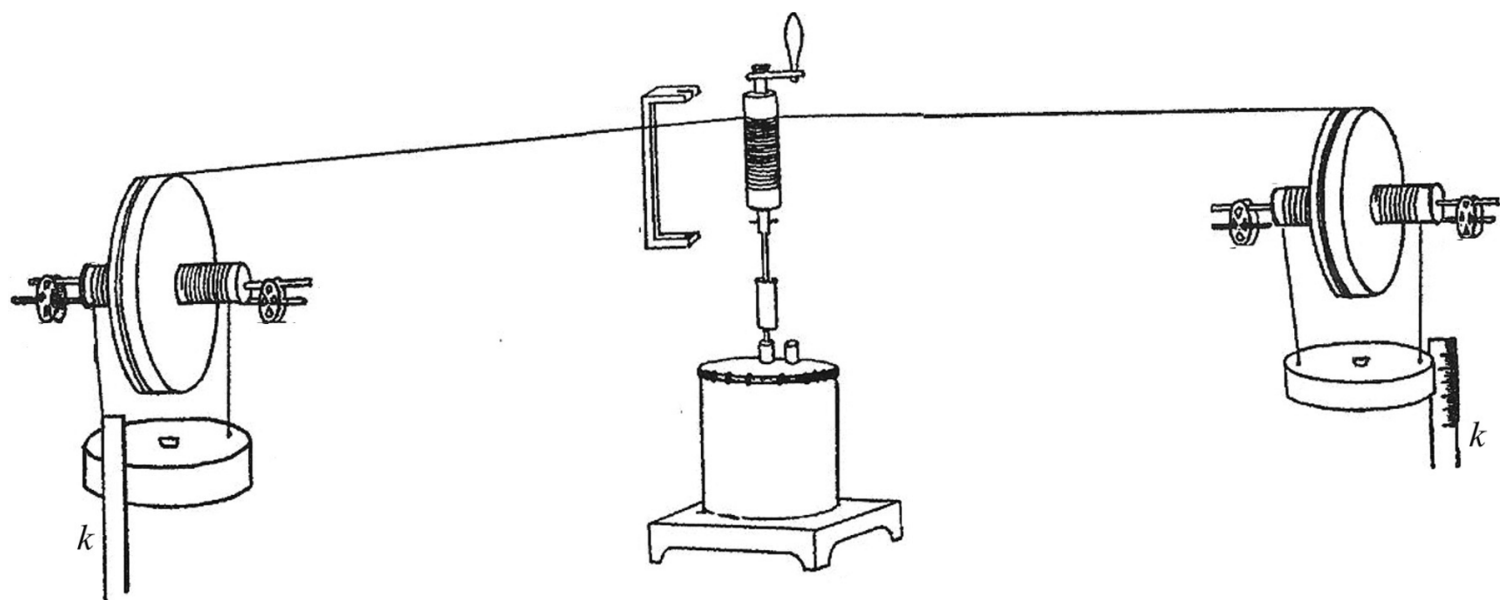

(a)

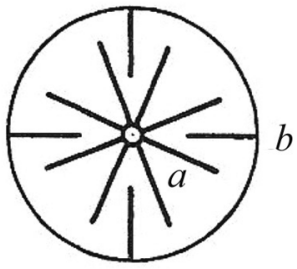

(b)

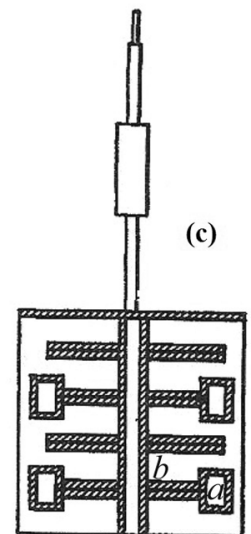

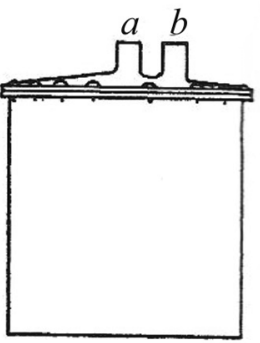

(d)

Figura 1 - (a) as duas polias e um rolo (b) eixo do aparelho de atrito na vertical, (c) eixo do aparelho de atrito na horizontal, (d) é um vaso de cobre em que o aparelho girando firmemente equipado com dois buracos na tampa, um para a inserção do eixo, e o outro para a inserção de um termômetro. 
Vejamos a descrição das medições feitas por Joule (1850):

O método de experimentação foi muito simples, como segue: - A temperatura do aparato de fricção foi verificada e os pesos foram elevados e fixos com ajuda do suporte h, o rolo estava preso ao eixo. A altura precisa dos pesos acima do solo foi determinada pelas réguas de madeira k, k, e o rolo foi liberado e deixado rolar até os pesos atingirem o chão do laboratório, o que correspondeu a uma queda de quase 63 polegadas. O rolo foi então removido do suporte, os pesos erguidos novamente, e a fricção refeita. Após a repetição deste procedimento por 20 vezes, o experimento foi concluído com outra observação da temperatura do aparato. A temperatura média do laboratório foi determinada com medições feitas no início, meio e no término de cada experimento.

Previamente, ou imediatamente após cada experimento, testei os efeitos da radiação e condução do calor da e para a atmosfera, seja no aumento ou diminuição da temperatura do aparato de fricção. Nestes testes, a posição do aparato, a quantidade de água contida nele, o tempo em utilização, o método de observar os termômetros, a posição do experimentador, durante um pequeno intervalo de tempo, com exceção de quando o aparato estava em repouso, permaneceram iguais em todos os experimentos em que o efeito de fricção era observado.

Joule explicou que repetiu o procedimento por 20 vezes para obter e registrar a temperatura. Este procedimento teve como objetivo diminuir erros e fazer as correções necessárias na obtenção do equivalente mecânico do calor. No entanto, mesmo com esse tratamento, o aumento de temperatura na água ainda era desprezível ao fim das 20 repetições. Cada experimento (soltando os pesos 20 vezes) levou 35 min. Como visto na Tabela 1, a tabela original do experimento, Joule registrou dados sobre a mudança de temperatura, número de repetições, a altura de queda de peso, etc.

Tabela 1 - Reprodução da tabela de dados do experimento de Joule, com notação da época.

\begin{tabular}{|c|c|c|c|c|c|c|}
\hline \multirow{2}{*}{$\begin{array}{l}\mathrm{N}^{\circ} \text { of experiment } \\
\text { and cause of change } \\
\text { of temperature }\end{array}$} & \multirow{2}{*}{$\begin{array}{l}\text { Total fall of } \\
\text { weights in } \\
\text { inches }\end{array}$} & \multirow{2}{*}{$\begin{array}{l}\text { Mean } \\
\text { temperature } \\
\text { of air }\end{array}$} & \multirow{2}{*}{$\begin{array}{l}\text { Difference } \\
\text { between mean of } \\
\text { columns } 5 \text { and } 6 \\
\text { column } 3\end{array}$} & \multicolumn{2}{|c|}{ Temperature of apparatus } & \multirow{2}{*}{$\begin{array}{l}\text { Gain or loss of } \\
\text { heat during } \\
\text { experiment }\end{array}$} \\
\hline & & & & $\begin{array}{l}\text { Commencement } \\
\text { of experiment }\end{array}$ & $\begin{array}{l}\text { Termmination } \\
\text { of experiment }\end{array}$ & \\
\hline 1 Friction... & 1256.96 & 57.698 & $2.252-$ & 55.118 & 55.774 & 0.656 gain \\
\hline 1 Radiation... & 0 & 57.868 & $2.040-$ & 55.774 & 55.882 & 0.108 gain \\
\hline 2 Friction... & 1255.16 & 58.085 & $1.875-$ & 55.882 & 56.539 & 0.657 gain \\
\hline 2 Radiation... & 0 & 58.370 & $1.789-$ & 56.539 & 56.624 & 0.085 gain \\
\hline 3 Friction... & 1253.66 & 60.788 & $1.596-$ & 58.870 & 59.515 & 0.645 gain \\
\hline 3 Radiation... & 0 & 60.926 & $1.373-$ & 59.515 & 59.592 & 0.077 gain \\
\hline 4 Friction... & 1252.74 & 61.001 & $1.110-$ & 59.592 & 60.191 & 0.599 gain \\
\hline 4 Radiation... & 0 & 60.890 & $0.684-$ & 60.191 & 60.222 & 0.031 gain \\
\hline 5 Friction... & 1251.81 & 60.910 & $0.431-$ & 60.222 & 60.797 & 0.575 gain \\
\hline 5 Radiation... & 0 & 61.033 & $0.237-$ & 60.797 & 60.799 & 0.002 gain \\
\hline 6 Radiation... & 0 & 59.675 & $0.125+$ & 59.805 & 59.795 & 0.010 loss \\
\hline 6 Friction... & 1254.71 & 59.919 & $0.157+$ & 59.795 & 60.357 & 0.562 gain \\
\hline 1 & 2 & 3 & 4 & 5 & 6 & 7 \\
\hline
\end{tabular}

Esta tabela tem 40 linhas [15]. Para o calor (radiação), Joule verifica a temperatura do ar, que pode variar ao longo do experimento. Considerando-se o calor específico do cobre e da água, que já eram conhecidos na época [16] e outros valores aproximados, Joule obteve a força equivalente ao aumento de $1^{\circ} \mathrm{F}$ por1 lbs de água.

Portanto $(6067.114 / 7.842299)=773.64$

pé-libras, ${ }^{\mathbf{\square}}$ será a força que, de acordo com os experimentos acima do atrito na água, é equivalente a $1{ }^{\circ} \mathrm{F}$ em uma libra de água [13, p. 312].

Joule fez ajustes, modificações, até encontrar um valor para o equivalente que fosse próximo daquele que ele mesmo já havia obtido nos experimentos com eletromagnetismo. Levou em consideração "várias fontes de erro como: a fricção das pás na parede do calorímetro, a rigidez das cordas que sustentavam os pesos, a força

\footnotetext{
${ }^{5}$ A reprodução do experimento do Joule pode ser encontrada em http://wWw .youtube.com/watch?v=MBrTDKc9YZ0\{\&\}feature=youtu. be

${ }^{6} \mathrm{O}$ que corresponde a necessidade de aproximadamente $4,184 \mathrm{~J}$ para elevar de $1{ }^{\circ} \mathrm{C}$ a temperatura de $1 \mathrm{~g}$ de água. A unidade "lbs" (libras) está sendo utilizada para medir a quantidade de água, ou seja, massa. Neste caso $1 \mathrm{lb}=450$ gramas. A unidade 1 pé-libra por minuto é unidade de potência e equivale a $0,023 \mathrm{~W}$. A unidade 1pé-libra é unidade de trabalho/energia e equivale a 1,356 J.
} 
desenvolvida pelas cordas depois que os pesos tocavam o chão, etc." [14]. Uma das fontes de erro era também o calor irradiado pelo equipamento e que aquecia o ar em torno dele. Joule considerou que para eliminar esta fonte de erro, era necessário que houvesse pouca diferença entre a temperatura da água no interior do calorímetro e do ar. Para isso, realizou o experimento no interior da adega de sua cervejaria.

Ele tinha conhecimento de que a precisão de suas medidas deveria ser grande para ser reconhecida perante a sociedade, e buscou pelos termômetros mais precisos que havia na época. Utilizando tais termômetros, ele comenta:

[a] prática constante permitiu-me ler com olhos nus até $1 / 20$ de uma divisão, seguiu que 1/200 de um grau Fahr. era uma temperatura apreciável [13, p. 303]

Isso dá uma margem de erro de $1 \%$ na leitura da temperatura para o experimento de Joule e consequentemente, uma precisão maior na determinação do equivalente do que seria obtido antes, como por exemplo nos trabalhos de Rumford, em que não houve tal acuidade [14].

Devemos lembrar que a experiência levou 35 min para detectar o aumento da temperatura a partir de $55,118{ }^{\circ} \mathrm{F}$ para $56,488^{\circ} \mathrm{F}$ (ambos os valores correspondem a ganho por fricção), ou uma variação de $1,37^{\circ} \mathrm{F}$. Apesar de Joule ter sido altamente metódico e meticuloso com todos os detalhes das experiências, suspeitamos que a variação é insignificante se a precisão do termômetro no século XIX for considerada, bem como todas as condições do experimento. É difícil entender como ele poderia encontrar tais leituras para temperatura próximas à $3^{\mathrm{a}}$ casa decimal com os limites tecnológicos dos termômetros da época. Assim, é relevante informar que os termômetros utilizados por Joule foram construídos por um certo Mr. Dancer, de Manchester, e, segundo Joule, foram os primeiros termômetros extremamente bem calibrados. O termômetro usado no calorímetro tinha $87 \mathrm{~cm}$ de comprimento, com bulbos de formato irregular, estava calibrado do ponto de congelamento até $85^{\circ} \mathrm{F}$. O volume do bulbo do termômetro era de aproximadamente $5 \mathrm{~cm}^{3}$ e o peso de mercúrio aproximadamente $68 \mathrm{~g}$, a espessura do vidro é de 0,08 cm e, à pressão de $1 \mathrm{~atm}$, o mercúrio sobe 5 divisões. Realizando vários testes com 50 temperaturas diferentes, Joule encontrou que, provavelmente, cada divisão do termômetro equivalia a $0,07723^{\circ} \mathrm{F}$ ou quase $1 / 13$ de $1^{\circ} \mathrm{F}[17]$.

Não há dúvida de que o resultado final é impressionante, pois é muito próximo do valor padrão atual. Não contestamos a importância e validade do experimento. Mas, gostaríamos de observar atentamente os valores de temperatura e de tentar entender a precisão do experimento.

\section{Nossa reprodução do experimento}

Tentando testar a precisão do experimento, em termos de aumento de temperatura, e sua complexidade, construímos um novo experimento utilizando materiais atuais. As condições estruturais do local onde o experimento foi replicado não nos permitiram reconstruir o original, uma vez que deveria ser observada a altura que os pesos descem, equipamentos de cobre e uma temperatura ambiente que não diferisse muito da temperatura da água no interior do recipiente (lembrando que Joule o realizou numa adega).

Partindo da leitura da descrição original do experimento, construímos um objeto com várias pás e conectamos a um motor elétrico. Em vez do cilindro de cobre, optamos por um calorímetro de plástico isolado por uma fina camada de isopor (Fig. 2 - (a) Perspectiva na vertical do calorímetro, (b) eixo do aparelho de atrito na horizontal).

Para medir a temperatura foi utilizado um sensor digital de temperatura de líquidos (Cidepe - Referência CL016), com precisão de $+/-10 \%$ captando valores de $-50 \mathrm{a}+150{ }^{\circ} \mathrm{C}$, que enviou os dados para um software específico (CidepeLabUSB), responsável por receber o sinal e converter os dados para uma planilha do Excel, o que nos permitiu gerar gráficos de elevação da temperatura.
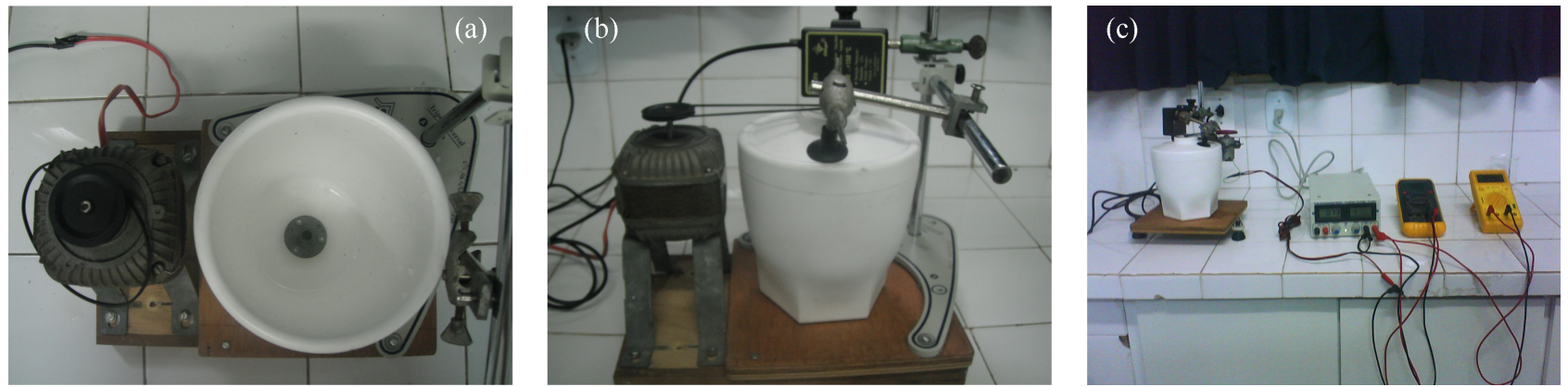

Figura 2 - (a) Perspectiva na vertical do calorímetro; (b) Aparato completo; (c) aparato e sensor para captar os dados. 
No primeiro experimento, foram utilizados 5 pedaços de madeira como pás (Fig. 3) e colocamos $200 \mathrm{~mL}$ de água no calorímetro. Neste primeiro teste, durante 20 min de fricção, obteve-se o incremento de 0,3 graus na temperatura, $31,1{ }^{\circ} \mathrm{C}-31,4{ }^{\circ} \mathrm{C}$. A temperatura ambiente era de 31 graus Celsius.

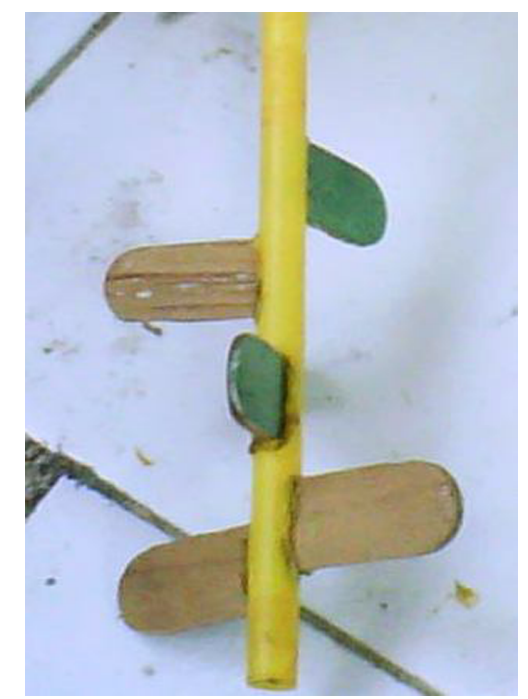

Figura 3 - Eixo de atrito com 5 pás.

Por considerarmos este ganho insignificante, se comparado com a perda de calor para o ambiente, fizemos algumas mudanças no experimento tentando obter melhores resultados. Com efeito, tentamos obter um maior aumento na temperatura num período menor de tempo, porque a experiência seria menos influenciada pela temperatura ambiente e teria menos perda de energia. Para isso associamos uma fonte de alimentação digital (0 a $30 \mathrm{VCC} / 5$ A) ao eixo com as pás.

As 5 pás requeriam uma grande quantidade de água para ficarem submersas. Para este volume de água seria necessária mais energia para o motor elétrico, e as pás não eram fortes o suficiente para a tarefa. Além disto, mais água significava mais trabalho para aumentar a temperatura, já que o calor específico da água é alto. No entanto, quando substituímos as pás de madeira por ferro, modificamos o formato (Fig. 4), o que necessitava de menor quantidade de água. Por outro lado, o eixo de ferro era mais pesado e tivemos que substituir o motor por outro mais potente para agitar a água.

Depois de alguns testes, concluímos que a turbina de ferro com duas pás poderia satisfazer os nossos requisitos: era possível agitar uma grande quantidade de água, porque o ferro era mais forte do que a madeira e, ao mesmo tempo, era suave o suficiente para a potência do motor elétrico utilizado (Fig. 5). Usamos $300 \mathrm{~mL}$ de água e obteve-se um aumento de 0,8 graus em $15 \mathrm{~min}$ como se pode verificar no Fig. 6 (gráfico da temperatura pelo tempo, temperatura ambiente de $27^{\circ} \mathrm{C}$ ).

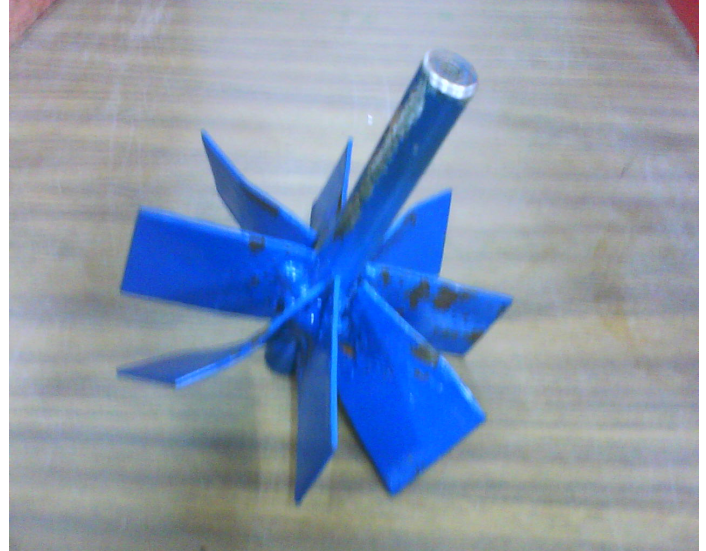

Figura 4 - Eixo de atrito com 8 pás.

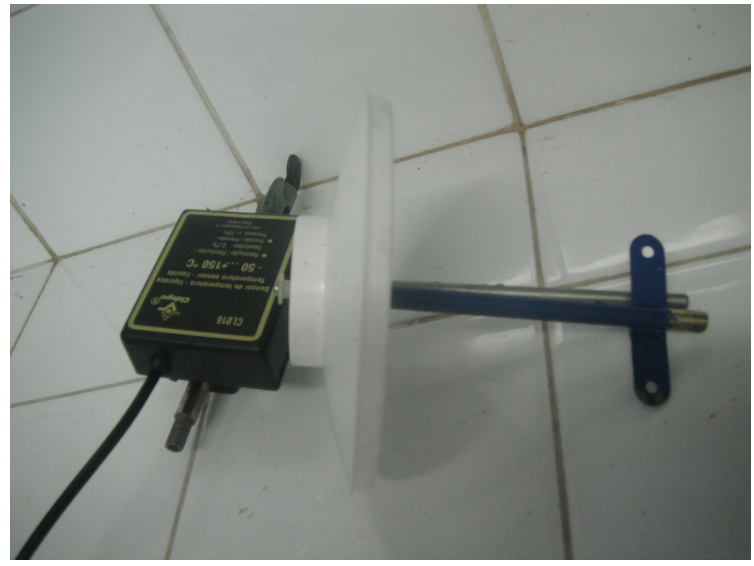

Figura 5 - Eixo de atrito final, com duas pás.

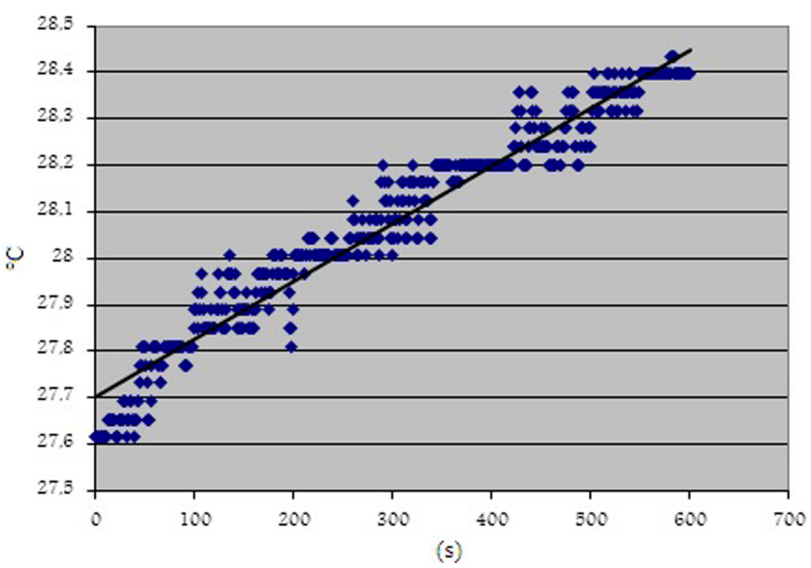

Figura 6 - Gráfico Tempratura vs. tempo.

\section{Discussão}

O experimento construído não permite determinar o equivalente mecânico do calor, porque há muitas trocas de energia a serem equilibradas para obter um resultado final. Em primeiro lugar, o calorímetro não é 100\% adiabático, nem sabíamos o seu calor específico. Tentando evitar uma perda de calor para o ambiente, trabalhamos com água à mesma temperatura que o ar do lado 
de fora do calorímetro. Este procedimento evita uma variação de temperatura entre o ar e a água e reduz a perda de calor. Em segundo lugar, a potência do motor elétrico usado não era tão precisa, uma vez que tivemos que adaptar o que já havia no laboratório. A energia elétrica do motor é convertida em energia cinética de rotação do eixo com pás. As moléculas de água perdem parte desta energia na forma de calor, aquecendo o ar à sua volta. Assim, a temperatura obtida corresponde ao calor obtido pelo trabalho mecânico do motor, mas não se pode fazer nenhuma afirmação sobre um valor padrão de equivalência entre trabalho mecânico e calor.

No entanto, o processo de construção e os resultados encontrados para os valores de temperatura mostram a dificuldade em se obter conclusões a partir dos experimentos. O sensor de temperatura digital utilizado tinha uma precisão de cinco casas decimais, e a cada segundo marcava-se o valor da temperatura. A temperatura inicial foi marcada $27,61486{ }^{\circ} \mathrm{C}$ e, após $10 \mathrm{~min}$, ou seja, 600 dados, a temperatura final foi de $28,39687^{\circ} \mathrm{C}$, ou seja, mesmo com esta precisão verificamos uma variação inferior a $1^{\circ} \mathrm{C}$, o que equivale a $33,8^{\circ} \mathrm{F}$.

Os equipamentos utilizados, adaptados, e o fator de erro que trazem impedem uma análise profunda das hipóteses teóricas que antecedem a experiência, qual seja, uma conversão de "forças" mensurável por um fator de equivalência. Vale ressaltar que sabíamos de antemão qual o resultado esperado, ou seja, sabíamos que tínhamos que medir durante um certo intervalo de tempo, que a temperatura iria aumentar, que tínhamos que ter um aumento considerável para a precisão do equipamento, etc. Todas estas suposições de "onde o experimento deveria chegar", não podem ser levadas em consideração quando iniciamos um projeto experimental, porque, a princípio, não são conhecidas. Sendo assim, qualquer resultado obtido pode ser considerado válido quando não se conhece o "correto" [18, p. 5].

Portanto se partíssemos apenas do problema posto à época, ou seja, de encontrar o equivalente mecânico do calor, como fez Joule, poderíamos ou não chegar a alguma conclusão, e ainda assim, talvez não fosse um resultado válido. Assim, temos que considerar que Joule partiu de um pressuposto inicial, seja teórico ou experimental, como os trabalhos já realizados por Rumford. Joule tinha conhecimento dos resultados obtidos por Rumford no experimento com o canhão e também das ideias de conservação de massa adotadas por Lavoisier na defesa do calórico. Portanto, o experimento foi realizado com uma base teórica - ainda que não matemática - e filosófica. Mesmo que colocasse em dúvida a precisão do resultado de Rumford, tal valor pode ter servido como um primeiro objetivo na realização do experimento.

Apesar de um pouco decepcionantes, os resultados encontrados não diminuem a importância do experimento de Joule e seu valor no contexto da história da ciência, ou mesmo do princípio de conservação da ener- gia. Consideramos que as dificuldades que encontramos enaltecem ainda mais o experimento de Joule para a compreensão da equivalência entre calor e trabalho, porém mostram sua fragilidade quanto ao aspecto de experimento crucial.

Além disso, precisamos considerar que, em 1850, quando foi apresentado, o experimento não atendia a um dos requisitos do fazer científico, que é a aprovação e reprodutibilidade dos resultados pelos pares. Isto não é possível com o experimento de Joule. Mesmo tendo sido extremamente descritivo, Joule não fornece vários elementos que tornariam possível a reprodução exata do experimento. Por exemplo, ele não fornece informação sobre o tipo de corda utilizada para subir ou baixar os pesos, a distância entre as pás e o eixo de rotação ou mesmo como lidar com certos problemas técnicos como a vibração do equipamento durante a movimentação das pás e a descida dos pesos [14].

\section{Considerações finais}

A reprodução de experimentos históricos como o caso apresentado aqui apresenta várias possibilidades de exploração do ponto de vista epistemológico e metodológico. O processo de reconstrução do equipamento, o estabelecimento das hipóteses, as conjecturas elaboradas para a solução dos problemas, bem como a análise dos resultados obtidos, mostram a complexidade do conhecimento científico e o papel dos experimentos.

Não foi nosso objetivo encontrar o equivalente mecânico do calor, como feito por Joule, nem mesmo partir para uma comprovação experimental de resultados teóricos, mas analisar todas as variáveis envolvidas antes e depois da realização do experimento, discutindo a validade e precisão dos dados em comparação com aqueles obtidos no século XIX.

O experimento escolhido já foi, e continua sendo, reproduzido em diferentes instâncias. Heinz Otto Sibum [19], procurou, a partir de 1990, seguir rigorosamente as poucas instruções adquiridas no texto original, e percebeu que não seria possível repetir a sequência mecânica tal como consta nas anotações e nos documentos de Joule. Em 1992, após uma série de considerações e testes, foi possível obter um valor para o equivalente calor de 746,89 ftlbs/BTU, depois com novos testes, obteve um valor de 772, 692 ftlbs, aproximando-se dos valores obtidos no experimento de Joule. Heering [14] também descreve como realizou a montagem do experimento e as dificuldades experimentais que encontrou. Nestes dois trabalhos, observamos que o foco dos autores se encontra na importância histórica do experimento, situandoo dentro do contexto experimental do século XIX.

Por outro lado, inúmeras montagens ocorrem nos laboratórios didáticos, tanto do Ensino Médio quanto do Superior. Neste caso, observamos que o foco dos autores, professores e alunos está no resultado da experiência. Estranhamente, mesmo não seguindo os pas- 
sos de Joule, ou realizando adaptações grosseiras como usando pesos mínimos, os resultados chegam muito próximos daqueles existentes na teoria! Diante dos desafios relatados aqui, como isso é possível?

Neste trabalho, a reprodução feita tentou se aproximar do procedimento experimental do cientista, ou seja, sob a perspectiva de um estudo realizado para a resolução de um problema imposto pelo contexto, e não de simples validação do resultado, o que o torna incomparável aos casos mencionados. Acrescenta-se que tal reprodução consiste em um dos elementos de uma intervenção a ser realizada em sala de aula. A utilização de experimentos históricos sob a perspectiva da resolução de um problema em aberto reproduz as dificuldades impostas aos cientistas e enriquece a atividade experimental em sala de aula, além de possibilitar a contextualização através da introdução de elementos de história da ciência.

\section{Agradecimentos}

As autoras agradecem ao Conselho Nacional de Pesquisa $(\mathrm{CNPq})$ e à Universidade Estadual da Paraíba (PROPESQ 2- UEPB) pelo apoio financeiro.

\section{Referências}

[1] P. Heering and R. Wittje, Science \& Education, DOI 10.1007/S1191-010-9334-Z (2011).

[2] I. Hancking, Representar e Intervir: Tópicos Introdutórios de Filosofia da Ciência Natural (EDUERJ, Rio de Janeiro, 2012).

[3] A.D.T. Gomes e A.T. Borges, R. Justi, Inv.Ens.Ciências 13, 187 (2008).
[4] J.R. Mayer, J.P. Joule and S. Carnot, ISIS 13, 1 (1929).

[5] R.A. Martins, Cad. Hist. Fil. Ciência 6, 63 (1984).

[6] P.M.C. Dias, Revista Brasileira de Ensino de Física 29, 493 (2007).

[7] T.S. Kuhn, A Tensão Essencial (Editora UNESP, São Paulo, 2011).

[8] S. Ross, Annals of Science 18, 65 (1962).

[9] L. Rosenfeld, in: Dicionário de Biografias Científicas, organizado por C.C. Gillispie (Contraponto, Rio de Janeiro, 2007).

[10] J.P. Joule, Abstracts of the Papers Communicated to the Royal Society of London, 5, 839 (1843a).

[11] J.P. Joule, Phil. Mag., xxiii, 123 (1843b).

[12] A.P. Chagas, in: O Saber Fazer e Seus Muitos Saberes: Experimentos, Experiências e Experimentações, organizado por A.M. Alfonso-Goldfarb, M. H. R. Beltran (Livraria da Física/EDUC/Fapesp, São Paulo, 2006).

[13] J.P. Joule, Scientific Papers (Physical Society, London, 1884).

[14] P. Heering, in: Proceedings of the Second International Conference on the History and Philosophy of Science and Science Teaching, editado por S. Hills (Queens University, Kingston, 1992).

[15] J.P. Joule, Phil. Trans. Royal Society of London 140, 61 (1850).

[16] J.C. Passo, Revista Brasileira de Ensino de Física 31, 3603 (2009).

[17] J.R. Ashworth, J. Sc. Inst. 7, 361 (1930).

[18] P. Galison, How Experiments End (Chicago University Press, Chicago, 1987).

[19] H.O. Sibum, Stud. Hist. Phil. of Science 26, 73 (1995). 